\title{
Back to the basics: using density series to test regulation versus limitation for invasive plants
}

\author{
Michael G. Munshaw $\cdot$ Christopher J. Lortie
}

Received: 11 December 2009/Accepted: 25 March 2010/Published online: 7 April 2010

(C) The Author(s) 2010. This article is published with open access at Springerlink.com

\begin{abstract}
Numerous hypotheses have been invoked to explain invasion in plant communities. Here, we use a fundamental tool from plant ecology, density series in situ, to explore whether a reasonable starting point for highly successful invasive plant species is to consider regulation (biotic effects) and limitation (environmental constraints). To explore the utility of density series to understanding invasion we present a case study using $C$. solstitialis, a perfect candidate since it is a prolific seed producer and invasive in many grasslands globally. Using seed addition into existing vegetation in three grasslands with densities of up to 6500 seeds per $\mathrm{m}^{2}$, we found no evidence for regulation via intra or interspecific interference but large differences amongst sites. This strongly suggests that in this species limitations imposed by the environment are the only constraints. Hence, we propose that an excellent starting point for ecologists studying invasion should involve back to the basics experiments on novel species to determine whether other hypotheses need be invoked.
\end{abstract}

Keywords Density · Grassland . Invasion $\cdot$ Seed

M. G. Munshaw · C. J. Lortie ( $\square)$

Department of Biology, York University, 4700 Keele St, Toronto, ON M3J 1P3, Canada

e-mail: lortie@yorku.ca

\section{Fundamental plant ecology concepts and invasion}

In plant ecology, density dependence is used as the primary means to infer whether regulation within a species is present or whether limitation by the environment prevails (Berryman 2004; Goldenheim et al. 2008; White 2001). Under the former scenario, interference or intra-specific competition may be present while under the latter instance lack of available microsites or resources limit opportunity for establishment. Previous studies using seed density have shown neutral, positive, and negative density effects depending on the species (Flores and Jurado 2009; Murray 1998; Poulsen et al. 2007), but weedy species can show either positive or neutral density effects (Palmblad 1968). This type of thinking has not been applied to invasive plant species in grasslands - yet the approach and methodology is elegant and simple. Here, we simply propose that in many instances there is no need to reinvent the wheel when studying invasive plants in grasslands when we can borrow insights from and adopt fundamental plant ecology techniques (Davis et al. 2001). More simply put, we propose that a general first principle hypothesis for successful invasive weed species is that they are free from intra-specific regulation in the field and are subject only to limitation by the local environment.

Density is the number of individuals per unit area and is a measure or an experimental factor generally applied to discrete populations (Gunton and Kunin 2007). This 'mean field' or neighbourhood-level approach to species 
density (Gunton and Kunin 2009) can also be scaled up to community-level manipulations (Goldberg et al. 2001; Lortie and Turkington 2002) whereby the total number of individuals for all species is increased. At both scales, population dynamics are inferred by comparing changing germination, recruitment, survival, etc. across densities. Positive density dependence or an increase in one of these response variables with increasing density is relatively uncommon in basic plant ecology experiments whilst negative density dependence or a decrease in performance measures is commonly reported for individual, specieslevel studies (Goldberg et al. 1999). A lack of these feedbacks in the responses of species to density is termed neutral density dependence and logically leads to the broader scope of ecological inquiry in plants and animals whether regulation or limitation is determining the relative abundance of a given species (White 2001). Regulation is best defined as the direct effects of other species (or intra-specific interactions) which reduce the numbers of a species below the capacity of the environment-sometimes called boundedness (Gunton and Kunin 2009; Hixon et al. 2002; White 2001). Limitation is the capacity of environment to support a certain number of individuals (White 2001). The primary implication to invasion studies of these basic ecological paradigms is that a step-wise approach in understanding introduced species could be used to determine whether interactions with other speciesincluding other individuals of that same species-are mediating its abundance or whether limitations in the environment prevail.

More specifically, there are a number of hypotheses that invoke regulation or direct biotic interactions as the controls for invasive plants including the diversity resistance hypothesis (Crawley et al. 1999), fluctuating resource availability through plant-plant competition (Davis et al. 2000), or enemy release (Keane and Crawley 2002) and evolution of increased competitive ability (Blossey and Notzold 1995) both predicated upon the absence of predators. Only two dominant invasion hypotheses rely on limitation as a means to explain the success of introduced species. The empty niche hypothesis is a hybrid of evaluating the abiotic environment and the relative contrast between the realized niches of native species and the fundamental niche of the introduced species (Levine and D'Antonio 1999) whilst the propagule pressure hypothesis proposes that available seed in a given environment and its density are critical factors in mediating the abundance of an introduced species (Lonsdale 1999). A classic plant ecology approach such as density series in the field thus provides the means to contrast the assumptions associated with the contemporary invasion literature and necessarily facilitates a parsimonious interpretation on the relative importance of other species in an invaded community.

The general method we propose is simple. Combine field seed sowing methodology with density series. Seed sowing experiments add seeds of a species to a community either at sites wherein the species is already present, i.e. augmentation, or into communities wherein the target species is not a member of the community, i.e. introduction (Turnbull et al. 2000). The former method examines the importance of additional seed in an environment where the species has already demonstrated successfully recruitment while the latter explores the importance of seed in overcoming barriers to both establishment and recruitment in novel contexts. Since the invasion literature provides numerous examples of highly successful species in various communities, we propose that seed sowing into already invaded communities more directly explores limitation versus regulation.

Density series or the addition of seeds at increasing numbers is a common method used to explore the importance of plant-plant interactions particularly competition (Gibson et al. 1999). These series also come in two flavours. Additive replacement series increase the number of individuals of each species in a mixture without a cap while replacement series hold the density constant but vary the relative proportions of each species (Jolliffe 2000; Taylor and Aarssen 1989). In both instances, performance in monoculture or pure mixtures is assumed to reflect only intra-specific interactions, and this treatment can be functionally similar in some designs. Given the heterogeneity of plant communities in density and the environment (Pausas and Austin 2001), the wide range of expression possible in an invasive plant species from almost no plants to virtual monocultures in an invaded region (Hierro et al. 2005), and that one invasive species is often studied at time in a system, the use of an additive series increasing the density of the invasive coupled with measurements of the density and diversity of the local species within the patch provides the most direct assessment of whether regulation controls the success of the target invasive species, i.e. competition, or if 
limitation in the environment determines success, i.e. density independence or positive dependence. By combining seed sowing and density series in the field into communities already invaded, this method integrates the importance of interactions intra and interspecifically with the capacity of the environment to provide suitable conditions for continued recruitment of the invasive.

\section{Case study}

Yellow starthistle (Centaurea solstitialis) is an ideal candidate to test the hypothesis that invasive species are free from regulation or direct interactions with other plant species. It is a highly invasive species in many countries including the United States infesting over 800 million acres of grassland in California alone (Callihan et al. 1992; Maddox et al. 1985). Efforts to control the spread of $C$. solstitialis have included livestock grazing, herbicide spraying, prescribed burning, and biological-control (Callihan et al. 1995). Nonetheless, this species remains widespread. Despite several studies exploring the management of this specific species (Benefield et al. 1999, 2001; DiTomaso et al. 2000; Thomsen et al. 1997) and a broad range of hypotheses associated with invasion generally invoked for success of weedy species (Callaway and Maron 2006), no study has manipulatively tested the importance of seed density in determining the likelihood of 'natural' field establishment i.e. whether regulation versus limitation are important considerations. Hence, $C$. solstitialis seeds were added to plots in 3 distinct grasslands near Davis, California. Plots $(0.5 \times 0.5 \mathrm{~m})$ were invaded with 0 (control for ambient seed), 100, 200, 400, 800 or 1600 seeds per plot on November 14 th \& 15th, 2007. Existing vegetation was left intact. In June 2008, the presence of adult $C$. solstitialis plants was recorded and soil cores were collected to assess the presence of remaining non-viable $C$. solstitialis seeds. Total richness and density of all other species in the plots was also recorded. A general linear model (GLM) was used to test for effects of the three sites tested, seed density, richness of all other species, and density of all other species in the plots on $C$. solstitialis seedling emergence. Where appropriate, regressions were then used to examine significant relationships, and in the case of seed density, non- linear fits with an $r^{2}$ at least $5 \%$ greater than linear were used to infer density dependent effects.

There were significant differences in seedling establishment between the three sites tested (GLM, Chi-square $_{\text {site }}=20.4, P=0.0001, \mathrm{df}=2,7$ ) with one site having double the establishment relative to the other two sites. C. solstitialis germination and establishment functioned independent of seed density at two of the sites while establishment was positively density dependent at one of the sites (Fig. 1a). This clearly indicates lack of regulation either intra-specifically or inter-specifically with existing vegetation present in the plots. Furthermore, species richness within the plots was unrelated to $C$. solstitialis emergence (GLM, Chi-square $_{\text {richness }}=0.1, P=0.74$, df $=1,7$ ) while density of all other plants within the plots was positively correlated to $C$. solstitialis seedling densities which also indicates a lack of regulation by the local species present in these grasslands $(\mathrm{Chi}$-square density $=$ $20.5, P=0.0001$, df $=1,7$; Fig. $1 b$ ). Hence, more invasive seeds leads to more invasive plants with no evidence, using this protocol, for increasingly negative interactions when density is dramatically increased (up to $6 \times$ reported levels in the soil) in this species.

This invasive weed species is not regulated in any way by intra-specific interactions between seeds or seedlings in the early life-stages. This is a highly novel finding in the invasion literature (but not for basic ecology) and intriguing in that insensitivity or positive responses to increasing density could be a common trait for invasive plant species. Admittedly, this a single season study and variations between seasons may lead to differential establishment by this species locally. Nonetheless, these findings clearly demonstrate that the method is sound (seed introductions at varying densities into established vegetation in situ) and that alternative and arguably less parsimonious hypotheses need not necessarily be invoked for this species. Hence, a reasonable starting point for plant ecologists studying invasion is to assess whether there is any evidence for regulation when an invader is already present in a system or whether availability of seeds and sites limit spread.

\section{Conclusions}

Using $C$. solstitialis, in already invaded systems, there was no evidence for regulation. More seeds lead to 
Fig. 1 a Regression of the relative differences between grassland sites in

C. solstitialis recruitment across density treatments. Mean $C$. solstitialis seedling recruitment is directly proportional to the number of seeds planted in Sites 1 and $3\left(r_{1}^{2}=0.74\right.$,

$P<0.001 ; r_{3}^{2}=0.99$, $P<0.001)$. Site 2 exhibits a non-linear increase in seedling recruitment relative to number of seeds planted $\left(r_{2}^{2}=0.93\right.$, $P=0.02)$. b Correlation of C. solstitialis recruitment relative to invaded plot vegetation density. The number of established yellow starthistle seedlings is positively correlated with vegetation density in all sites $(P<0.001)$
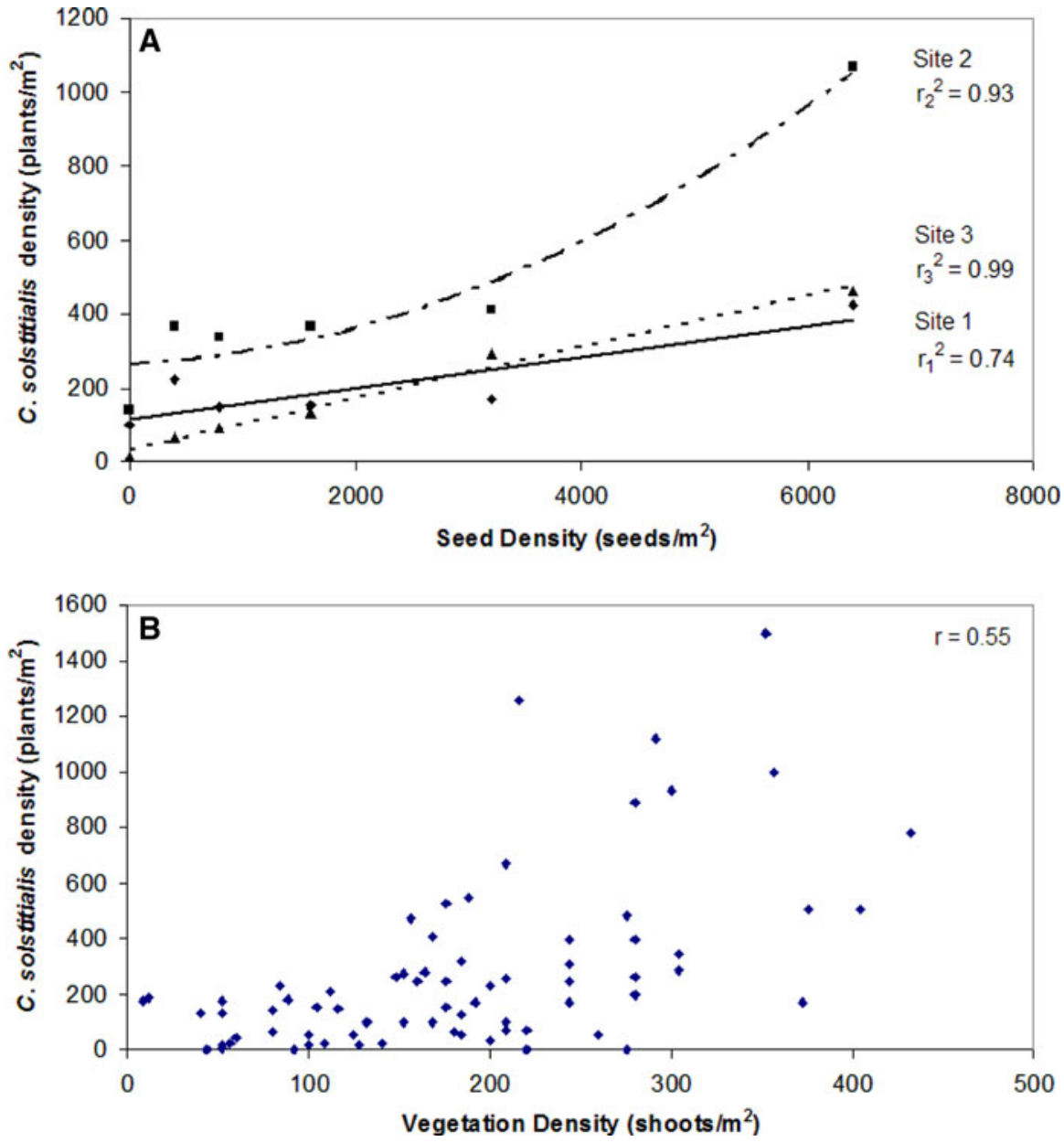

more plants, and more neighbouring plants of other species in either density or diversity did not negatively impact this invasive plant species. Regulation-based invasion hypotheses which rely on interference such as the diversity resistance hypothesis do not explain the success of $C$. solstitialis once it is present within a grassland. This is not to say that initial invasion into a naïve system cannot be explained by invasion hypotheses involving release from competition, but it is evident that limitation in the environment is clearly the critical set of factors mediating the expression of this highly noxious weed likely including presence of its propagules. The method tested, seed sowing with density series, is simple and easy to test for any invasive plant species that recruits from seeds. The importance of local patch dynamics can also be examined via application of seeds to multiple grasslands within a region, and if limitation is important, then management implications are clear. In this species for instance, depletion of the seedbank is the best method of control since plant-plant interactions may be relatively unimportant in degraded grasslands.

Acknowledgement This research with funded by an NSERC DG to CJL.

Open Access This article is distributed under the terms of the Creative Commons Attribution Noncommercial License which permits any noncommercial use, distribution, and reproduction in any medium, provided the original author(s) and source are credited.

\section{References}

Benefield CB, DiTomaso JM, Kyser GB, Orloff SB, Churches KR, Marcum DB, Nader GA (1999) Success of mowing to control yellowstarthistle depends on timing and plant's braching form. Calif Agric 53:17-21 
Benefield CB, DiTomaso JM, Kyer GB, Tshohl A (2001) Reproductive biology of yellow starthistle: maximizing later-season control. Weed Sci 49:83-90

Berryman AA (2004) Limiting factors and population regulation. Oikos 105:667-670

Blossey B, Notzold R (1995) Evolution if increased competitive ability in invasive nonindiginenous plants: a hypothesis. J Ecol 83:887-889

Callaway RM, Maron JL (2006) What have exotic plant invasions taught us over the past 20 years? Trends Ecol Evol 21:369-374

Callihan RH, Prather TS, Northam FE (1992) Recolonization strategies and longevity of yellow startthistle achenes in soil. Knapweed 6:3-4

Callihan RH, Smith L, Michalson EL (1995) Yellow starthistle management for small acreages. University of Idaho College of Agriculture Current Information Series 1025: 4-5

Crawley MJ, Brown SL, Heard MS, Edwards GR (1999) Invasion-resistance in experimental grassland communities: species richness or species identity? Ecol Lett 2:140-148

Davis MA, Grime JP, Thompson K (2000) Fluctuating resources in plant communities: a general theory of invasibility. J Ecol 88:528-534

Davis MA, Thompson K, Grime JP, Charles S (2001) Elton and the dissociation of invasion ecology from the rest of ecology. Divers Distrib 7:97-102

DiTomaso JM, Kyser GB, Orloff SB, Enloe SF (2000) Integrated approaches and control option considerations when developing a management strategy for yellow starthistle. Calif Agric 54:30-36

Flores J, Jurado E (2009) Effect of seed density on germination of Isolatocereus dumortieri and Myrtillocactus geometrizans, endemic columnar cacit species from Mexico. Rev Mex Biodivers 80:141-144

Gibson DJ, Connolly J, Hartnett DC, Weidenhamers JD (1999) Designs for greenhouse studies of interactions between plants. J Ecol 87:1-16

Goldberg DE, Rajaniemi T, Gurevitch J, Stewart-Oaten A (1999) Empirical approaches to quantifying interaction intensity: competition and facilitation along productivity gradients. Ecology 80:1118-1131

Goldberg DE, Turkington R, Olsvig-Whittaker L, Dyer AR (2001) Density dependence in an annual plant community: variation among life history stages. Ecol Monogr 71: 423-446

Goldenheim WM, Irving AD, Bertness MD (2008) Switching from negative to positive density-dependence among populations of cobble beach plant. Oecologia 158:478-482
Gunton RM, Kunin WE (2007) Density effects at multiple scales in an experimental plant population. J Ecol 95:435445

Gunton RM, Kunin WE (2009) Density-dependence at multiple scales in experimental and natural plant populations. J Ecol 97:567-580

Hierro JL, Maron JL, Callaway RM (2005) A biogeographical approach to plant invasions: the importance of studying exotics in their introduced and native range. J Ecol 93:5-15

Hixon MA, Pacala SW, Sandin SA (2002) Population regulation: historical context and contemporary challenges of open vs. closed systems. Ecology 83:1490-1508

Jolliffe PA (2000) The replacement series. J Ecol 88:371-385

Keane RM, Crawley MJ (2002) Exotic plant invasions and the enemy release hypothesis. Trends Ecol Evol 17:164-170

Levine JM, D'Antonio CM (1999) Elton revisited: a review of evidence linking diversity and invasibility. Oikos 87:15-26

Lonsdale WM (1999) Global patterns of plant invasions and the concept of invasibility. Ecology 80:1522-1536

Lortie CJ, Turkington R (2002) The effect of initial seed density on the structure of a desert annual plant community. J Ecol 90:435-445

Maddox DM, Mayfield A, Poritz NH (1985) Distribution of yellow starthistle (Centaurea solstitialis) and Russian knapweed (Centaurea repens). Weed Sci 33:315-327

Murray BR (1998) Density-dependent germination and the role of seed leachate. Aust J Ecol 23:411-418

Palmblad IG (1968) Competition in experimental populations of weeds with emphasis on the regulation of population size. Ecology 49:26-34

Pausas JG, Austin MP (2001) Patterns of plant species richness in relation to different environments: an appraisal. J Veg Sci 12:153-166

Poulsen JR, Osenberg CW, Clark CJ, Levey DJ, Bolker GM (2007) Plants as reef fish: fitting the functional form of seedling recruitment. Am Nat 170:167-183

Taylor DR, Aarssen LW (1989) On the density-dependence of replacement series. J Ecol 77:975-988

Thomsen CD, Vayssieres MP, Williams WA (1997) Mowing and subclover plantings suppress yellow starthistle. Calif Agric 51:15-20

Turnbull L, Crawley M, Rees M (2000) Are plant populations seed-limited? A review of seed sowing experiments. Oikos 88:225-238

White TCR (2001) Opposing paradigms: regulation or limitation of populations? Oikos 93:148-152 